\title{
Waiting Experience in Railway Environments
}

\author{
Mark Van Hagen \\ Netherlands Railways, Utrecht, the Netherlands
}

\author{
Mirjam Galetzka, Ad Th. Pruyn \\ University of Twente
}

\begin{abstract}
At railway stations, waiting time is usually an unavoidable aspect of the journey for train passengers. According to the attentional model of time, pleasant surroundings and other forms of distraction reduce perceived waiting time. Not every individual reacts identically in the same surroundings. Passengers in different states of mind enter the station every day. The authors propose that for recreational "lust" passengers, a stimulating environment initiates a more positive waiting time experience, whereas goal oriented "must" passengers respond more positively to a calming environment. A virtual railway station was developed to create a waiting environment in which the arousal level of environmental stimuli (stimulating or calming) was manipulated by the use of colored lighting (study 1) and background music (study 2) in an environment that varied in the degree of density. Results showed that at quiet low-density moments, passengers experienced greater pleasure when stimulating music was played, whereas at busy high-density moments it was the other way around (greater pleasure with calming music). Overall, "lust" passengers seemed more receptive to stimulating environments than "must" passengers. Pleasure increased and the waiting experience improved (with shorter time estimates). In line with reversal theory, the findings shed light on the relationship between environmental stimuli and waiting experience, including the differentiation between low- and high-density surroundings and motivational states of passengers. Designers of waiting environments might choose to design an environment that reverses negative emotions of boredom or stress to positive emotions of excitement and relaxation.
\end{abstract}

Keywords: waiting experience, waiting environment, time perception, reversal theory, railway station

Waiting time is an important part of the journey for train passengers but little is known about the waiting experience and how this is related to the waiting environment and time perception. The rail sector has long been measuring objective waiting times, but has never really gone into the question of the subjective waiting experience. Passengers generally dislike waiting and often overestimate how long they have actually been waiting. At the same time, travel and waiting time is a decisive factor in the choice of transportation. Research and investments in the railway sector have long been aimed at shortening the train journey, particularly with the optimization of the objective waiting and travelling time (Mackie, Fowkes, Wardman, Whelan \& Bateson, 2001; Peek \& Van Hagen, 2002; Wardman, 2004). These efforts are geared to

Mark Van Hagen, Netherlands Railways, Utrecht, the Netherlands; Mirjam Galetzka, Behavioural Sciences, University of Twente; Ad Th. Pruyn, Behavioural Sciences, University of Twente.

Correspondence concerning this article should be addressed to Mirjam Galetzka, Behavioural Sciences, University of Twente, PO Box 217, 7500 AE, Enschede, the Netherlands, E-mail: m.galetzka@utwente.nl minimize the wait at the station and thus to accommodate the time shortage of passengers. Less attention is paid to the passengers waiting at the station and how they experience this wait, i.e. the subjective waiting and travelling time. Yet this subjective (waiting) time perception was shown to be a good predictor of customer satisfaction, along with the influence of an attractive waiting environment (Pruyn \& Smidts, 1998; Taylor, 1994). This article aims to contribute more insight into the perception and evaluation of waiting time at Netherlands Railways (NS) stations.

Generally speaking, waiting time is unavoidable in many service settings and is usually considered to be an annoying aspect of customer experience with a negative impact on emotion (e.g., Cameron, Baker, \& Peterson, 2013; Hui, Dube, \& Chebat, 1997; Katz, Larson, \& Larson, 1991; Taylor, 1994, 1995). Reversal theory proposes that in different situations people will show divergent reactions dependent on the motivational state they are in (Apter, 2007). Waiting in line for the cash desk of your local supermarket or entrance of a museum is a situation in which people usually feel either bored (i.e., wasting your time with nothing to do) or anxious (i.e., worrying about being too late). In these states, people are more focused on time and time seems to drag on and go too slowly. However, when we are distracted by an entertain- 
ing environment time seems to pass more quickly. Designers of waiting environments might choose to design an entertaining environment that not only reverses negative emotions of boredom or stress to positive emotions of excitement and relaxation, but also influences the subjective experience of a positive wait. The design of the environment is of key importance to facilitate reversal to a more positive waiting experience.

When people are actively engaged and distracted during the wait, or can wait in pleasant surroundings, the wait is experienced as more pleasant (Hornik, 1992, 1993; Katz et al., 1991; Pruyn \& Smidts, 1998). In the enjoyment of the moment time simply melts away. Time flies when you're having fun! When attention is distracted from time, consumers notice their environment and can even enjoy their waiting time (e.g., Van Hagen, 2011; Zakay, 1989; Zakay \& Block, 2004).

In a railway station, people in different states of mind enter the station every day. We propose that two groups of passengers can be distinguished, which we call "must" and "lust" passengers (c.f., Steg, 2005; Van Hagen, 2011). "Must passengers" are people who regularly and systematically travel by train, such as commuters. They tend to be in a goaloriented telic state, in a hurry, less receptive to distraction in their surroundings, and more preoccupied with information processing and watching the time. Time for this type of passenger is of the essence. After all, a train departs at a prescheduled time. "Lust passengers", on the other hand, are people who are on an incidental journey (i.e., social or recreational transport), and tend to be in a more recreational paratelic state, less in a hurry, more receptive to distraction and a stimulating environment, and less focused on the clock (Van Hagen, 2011). Apparently, "lust" and "must" passengers have a different focus on time.

A few studies have been published over the years on how the process of estimating time actually works. The most important of these studies were the storage size model (Ornstein, 1969) and the attentional model (Zakay, 1989).

Ornstein (1969) presupposed that the sense of time in retrospect is a positive linear function of the complexity of the number of stimuli. He employed the metaphor of neurological storage capacity and alleged that time takes longer the more units of information (discrete events) are stored per event, the more events take place, the more events differ from one another and the more complex events are. Hence, a period in which nothing seems to happen is experienced (in retrospect) as having passed more quickly than one in which many different and complex activities took place. The more attention we pay to external stimuli, the more impressions we gather that we can remember, and the more subjective time can be ascribed to all those memories. As a result, the period seems to have lasted longer.

Zakay (1989) hypothesized that time estimation is a cognitive process whereby each stimulus is perceived by two processors: 1) a timer that processes time information, and 2) a processor that processes timeless (i.e. not time-bound) information.

According to the attentional model, during an interval, attention can be processed in both ways. Temporal processing implies that people are consciously aware of the passing of time (for example, by guessing how long one has already been waiting). Non-temporal processing is the pondering on issues that are not time-related. The more temporal information that is processed, the longer the interval seems. Pleasant surroundings, information, activities and other forms of distraction result in less information being temporally processed, which in turn reduces the perceived waiting time (Baily \& Areni, 2006).

So the way information is processed, and the attention to that information has an influence on our sense of time. The two main differences between the storage size and attentional model are: a) The attentional model is about the experience of the duration of time in the moment while the storage size model is about the experience of the duration of time afterwards; and b) the attentional model indicates that episodes with many events/stimuli are perceived as shorter, while the storage size model indicates that episodes with many events/stimuli are perceived as longer - i.e. an opposite result.

\section{Environmental stimuli and waiting experience}

When it comes to the experience of waiting time, a distinction may be made between actual (objective) waiting time and the subjective experience of the waiting time (Katz et al., 1991; Pruyn \& Smidts, 1998). Usually, waiting is considered a negative aspect of the service experience and time seems to drag on (Baker \& Cameron, 1996). Adverse effects of waiting on satisfaction with the service may be soothed by improving the attractiveness of the waiting environment rather than by shortening the objective waiting time (Pruyn $\&$ Smidts, 1998). The design of a waiting environment may help customers to reverse from a negative waiting experience into a positive one. Therefore, it is crucial for service providers to develop customer atmospheres that can redress the negative experience of waiting, so that passengers feel relaxed or distracted from waiting.

Environmental stimuli influence cognitive and affective processes that in turn determine approach or avoidance behavior (Mehrabian \& Russell, 1974). The environment influences, through its degree of arousal, the hedonic tone, the sense of control and the waiting experience. Together these three factors determine approach or avoidance behavior.

In the context of railway stations, crowding conditions have a strong impact on arousal levels, because it might be either extremely busy during peak hours or extremely quiet during off peak hours. High human density (i.e., high levels of crowding) goes hand in hand with an increase in arousal 
Table 1

Framework of environmental stimuli, congruency and emotions

\begin{tabular}{lll}
\hline Arousal level of stimuli + Density + Passenger state of mind & Congruency & Emotion \\
\hline stimulating stimuli + crowded + "must" & non-congruent & Anxiety \\
stimulating stimuli + crowded + "lust" & congruent & Excitement \\
calming stimuli + quiet + "must" & congruent & Relaxation \\
calming stimuli + quiet + "lust" & non-congruent & Boredom \\
\hline
\end{tabular}

and psychological stress (Baker \& Wakefield, 2012; Hui \& Bateson, 1991; Stokols, 1972; Worchel \& Yohai, 1979). Grewal, Baker, Levy and Voss (2003) demonstrated in a simulated store environment that high levels of perceived human density were related to stimulus overload and longer waiting time perceptions. Too little density may also evoke negative responses, especially in hedonic environments (e.g., bar, disco) where too little human density might feel tedious and result in mere boredom (Pons, Laroche, \& Mourali, 2006; Turley \& Milliman, 2000). Ang, Leong, and Lim (1997) suggested that consumers who seek different levels of arousal in their service consumption respond differently to arousal inducing elements of the environment. For example, in a banking environment, consumers typically do not seek arousal (tension) but are more likely to seek assurance and relaxation, whereas in amusement parks consumers tend to be thrill-seeking and looking for arousal from the environment.

In general, people experience control when the environment facilitates goal attainment (i.e., toward getting on the train in time, freedom to act, or enjoying the stay) (Prohansky, Ittelson, \& Rivlin, 1974; Ward \& Barnes, 2001). In considering the effects of human density, sense of control has been shown to be a key variable of interest (Dion, 2004; Hui \& Bateson, 1991; Van Rompay, Galetzka, Pruyn, \& MorenoGarcia, 2008). In railway stations, sense of control relates to two types of goals. For railway passengers, prevailing goals in a railway station are to arrive at the station in time and find their way as efficiently as possible. Such goals may be considered primarily functional. "Must" passengers tend to be task oriented toward attainment of functional goals. However, during off peak hours (i.e., when density is low), stations allow for relatively easy wayfinding, and functional goals may become less important. Under these circumstances, passengers may be more attuned to distraction and a pleasant and stimulating environment. "Lust" passengers tend to be oriented toward recreational and experiencerelated goals. An attractive waiting environment facilitates these goals, and will result in a more positive waiting experience.

\section{Conceptual model}

We hypothesize that the combination of the arousal level of environmental stimuli (stimulating or calming), density (quiet or busy), and motivational orientation ("must" or "lust") determine how passengers experience the platform and the wait. Depending on the context, two levels of optimal stimulation can be distinguished that are expected to influence hedonic tone (Apter, 2007).

Various authors have found that the degree of congruence of the number of stimuli in relation to the motivational orientation of the consumer and the perceived crowdedness determines the experienced pleasure. According to Massara, Liu and Melara (2010), a high level of pleasure is attained with an optimal level of activation. Here, optimal is to say an optimal level of stimulation that leads to an optimally pleasant experience, the so called hedonic tone (Apter, 2007). Specifically, goal-directed consumers experience more pleasure with little arousal and much dominance (i.e., the degree that the consumer has or perceives having control over the situation) and non-goal-directed consumers experience more pleasure with much arousal and little dominance. Situations where there are many environmental stimuli, such as a busy platform, demand a great deal of mental attention and may be experienced as too stimulating, whereas lack of stimuli (i.e., on a very quiet platform), may be felt to be tedious. By combining the framework of Massara et al. (2010) with the states of Apter's reversal theory (2007) we have developed Table 1 , which shows that four groups may be distinguished. The table also shows our hypothesized emotional responses.

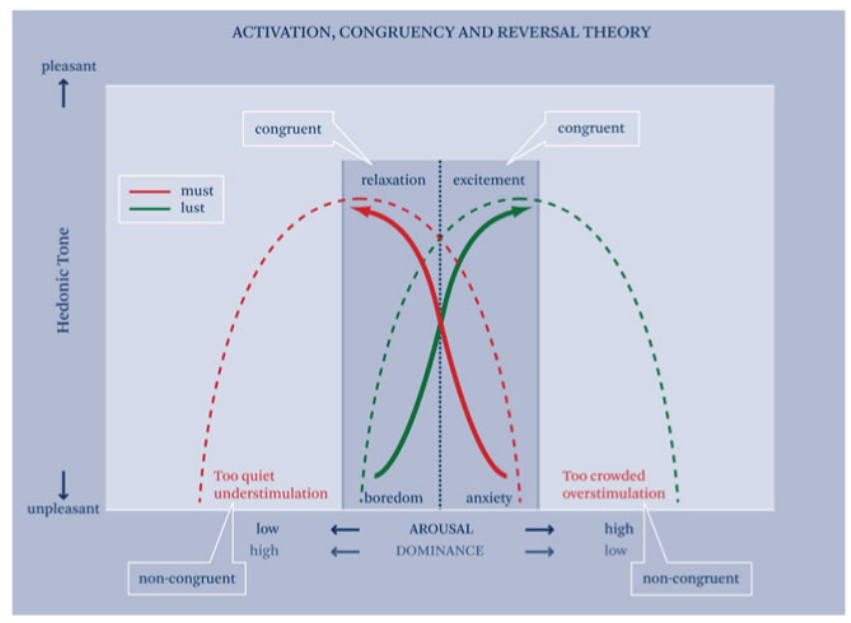

Figure 1. Elements of research design. 
As can be seen in Figure 1, high arousal levels induced by a stimulating environment (high density and stimulating stimuli) are hypothesized to result in excitement for "lust" passengers, and anxiety for "must" passengers. Low arousal levels (low density and calming stimuli), on the other hand, are predicted to induce mere boredom for "lust" passengers and relaxation for "must" passengers.

In sum, reversal theory poses that the response to environmental stimuli is dependent on context, such as degree of density on the platform and the motivational orientation of the customer. We expect that goal-oriented "must" passengers want to avoid too many stimuli. They are, after all, in the telic state and are concentrated on catching their train. For these passengers too many stimuli (i.e., stimulating environmental stimuli and high density) will induce stress and a lower hedonic tone. "Must" passengers are cognitively engaged in the processing of information and keep their eye on the clock. They are also expected to be less receptive to stimuli and aspire more to peace and quiet. In comparison, we predict that "lust" passengers will be more receptive to environmental stimuli; that they are in the paratelic state, less goal-oriented, and receptive to any distraction from boredom.

Hence the following hypotheses are proposed:

H1: A stimulating environment initiates a more positive station and waiting experience for "lust" passengers than for "must" passengers

$\mathrm{H} 2$ : A calming environment initiates a more positive station and waiting experience for "must" passengers than for "lust" passengers.

Environmental stimuli may also offer distraction from waiting. The attentional model (Zakay \& Block, 1997) poses that people pay less attention to the time when they are occupied in a non-time-bound activity, such as listening to music, and that the wait therefore seems to be shorter. Passengers pay less attention to the time when they are distracted and are thus less capable of estimating how long they have waited. We do expect, however, that "lust" passengers will estimate the wait as being shorter. On the basis of reversal theory, it can be expected that a stimulating environment increases the arousal of the waiting "lust" passenger more and that this will lead to a positive affective reaction. By giving passengers a more positive feeling, the wait will be experienced as less boring (Chebat, Filiatrault, Gelina-Chebat, \& Vaninsky, 1995; Gardner, 1985; Mayer et al., 1992; Pruyn \& Smidts, 1998) and lead to a shorter time perception (Baker \& Cameron, 1996; Hornik, 1984, 1992). Based on our expectation that in a quiet waiting environment "lust" passengers experience more distraction from stimulating than from calming stimuli, the following hypothesis is proposed:

H3: In a low density environment, "lust" passengers experience a shorter perceived waiting time with stimulating as opposed to calming environmental stimuli.
We do not expect any difference in time estimations for "must" passengers, because they are totally focused on the travel process and do not allow themselves to be distracted.

Nine field and virtual reality studies were completed that distinguish between two different environments: a stimulating versus a calming one. Three studies focused on the impact of visual environmental stimuli (color and lighting) in an actual railway station (field study), a virtual reality laboratory, and an online simulation. Three studies focused on the impact of auditive stimuli (background music, musical tempo and musical genre) in an actual railway station and an online visualisation. Three other studies focused on the impact of advertising and digital signage in a field setting and an online visualisation (pace of advertising and programming content) (for a complete overview of the nine studies see Van Hagen, 2011). Here we report the findings of two online studies, in which the arousal level of environmental stimuli (stimulating or calming) was manipulated by the use of colored lighting (study 1) and background music (study 2) in a virtual station environment that varied in the degree of density (low density or high density). We decided to elaborate on these two studies, because in an online environment we were able to manipulate more experimental factors, which gives richer results.

\section{Study 1: Colored lighting}

We choose to manipulate colors and light intensity, because these environmental stimuli are relatively easy to be changed into different settings, and colors and light are known for their impact on people's affect, cognition, and behavior (e.g., Biner, Butler, Fischer, \& Westergren, 1989; Elliot \& Maier, 2014). What kind of effect color has on people depends on the context (Elliot \& Maier, 2014). For instance, blue is considered to be a pleasant color, but blue food is not expected to elicit pleasant reactions (Valdez \& Mehrabian, 1994). Although effects of colors depend on context, there are some universal findings. Overall, colors with a short wavelength are known as cool colors, such as violet and blue. These colors are often preferred by people, and described to have a relaxing effect. Colors with a long wavelength, such as yellow, red and orange, are known as warm colors and often found to have a stimulating effect (e.g., Adams \& Osgood, 1973; Jacobs \& Suess, 1975; Valdez \& Mehrabian, 1994; Walters, Apter, \& Svebak, 1982; Yildirim, AkalinBaskaya, \& Capanoglu, 2011).

In accordance with reversal theory, it was hypothesized that "must" passengers want to avoid too many stimuli, which will lead to a negative station and waiting experience for "must" passengers. "Lust" passengers will be more receptive to environmental stimuli and a stimulating environment will initiate a positive station and waiting experience for this type of passenger. 
Also human density and light intensity may influence the station evaluation and time experience. As the effects of color depend on context, lighting effects have also been shown to depend on the situation, the task, and one's surroundings (Biner et al., 1989; Butler \& Biner, 1987). In a busy environment, the sense of control can decrease and lead to stress, so having a clear view is of paramount importance, which in turn necessitates a higher level of lighting (Van Bommel \& Van den Beld, 2004). In a quiet and less task-directed environment, the brightness of the lighting is less relevant, and too much light may even overstimulate. We thus expect that a low level of lighting in a quiet, low density environment and a high level in a busy high density environment will positively affect the hedonic tone and the waiting experience.

\section{Method}

Participants. Participants were panel members of the NS panel who have voluntarily stated that they wish to participate in NS research. In total 1,326 respondents (43.4\% female and 56.6\% male, $M d n$ age range 30-39 years) participated in the online study.

Design and stimulus materials. The study employs a three color (blue vs. red vs. yellow) $\mathrm{x}$ two light intensity (low vs. high) $\mathrm{x}$ two density (low vs. high) $\mathrm{x}$ two motivational orientation ("must" vs. "lust") between-subjects design.

A virtual world was created to study the effects of environmental manipulations (i.e., color, lighting, and density at the station). A replica was made of Leiden Central station in the Netherlands, where participants could assume the form of an avatar, and move through the railway station using a mouse. Leiden was chosen as it is the fifth largest station in the Netherlands and each type of passenger is well represented there. The participants could enter and freely navigate through the station from a first-person perspective, i.e., they were able to walk through the station, climb the stairs, and go onto the platform. Real-life background noises were played during the session to enhance imaginative power. Test subjects started the virtual world on the forecourt of Leiden Central Station and were asked to take the train to Amsterdam. They were free to navigate with their mouse through the entire station and with the aid of departure boards, clocks and/or announcement messages could find the correct train in time. Once the test subjects had ascertained where their train would depart from, they navigated to the correct platform and waited for the train. When it arrived, they clicked on the train and were subsequently led to a questionnaire. After answering it, the test subjects were thanked for their cooperation and the window closed.

The ecological validity of the use of virtual environments has already been shown (Blascovich, Loomis, Beall, Swinth, Hoyt \& Bailenson, 2002; Massara, Liu \& Melara, 2010; Riva, Mantovani, Capideville, Preziosa, Morganti, Villani et al., 2007). The advantage of a virtual environment is that it also meets the recommendation of Bateson and Hui (1992) to imitate ambient sounds that strengthen the ecological validity. In sum, the findings in a replicated environment are expected to be generally comparable with an actual environment.

After opening the start page, each participant was instructed to get the first train to Amsterdam. Then participants were asked to imagine themselves in a goal-directed "must" scenario ("... you have an appointment that is really important for you, so it is imperative that you arrive on time"), or a non goal-directed "lust" scenario ("With nothing planned tonight..., it does not matter when you get there, so you can take your time"). This role playing method has been successfully used in other studies in the service environment (e.g., Ang et al., 1997; Bitner, 1990; Folkes, 1984; Suprenant \& Solomon, 1987). In order to ensure that the scenario belonging to either the "must" or "lust" condition was actually perceived as such by the respondents, a pre-test was carried out. Twenty respondents were given one of two scenarios, following which they had to fill in a short questionnaire comprising four items from the Motivational Orientation Scale of Kaltcheva and Weitz (2006, $\alpha=.79)$. A t-test was conducted to compare the scores for motivational orientation. "Must" passengers $(M=4.8, S D=1.32)$ scored significantly higher for motivational orientation than "lust" passengers $(M=2.87, S D=1.19), t(18)=3.42, p<.01$. We could thus deduce that the scenarios were suitable and would lead to the desired effects.

Density was manipulated by placing either few or many other 'passengers' on the platform, just as experienced during peak and off peak hours in the real world (see Figure 2).

In the virtual station, color (blue, yellow and red) and brightness of light were projected on the canopy of the platform, as shown in Figure 2. We choose to manipulate the canopies, because all passengers can see that clearly, even if the platform is crowded. Level of color saturation was held constant for each condition.

Procedure. Panel members received an email in which they were asked to participate in the study. They could log in at any time and via a link they arrived at the introduction page where they were asked to download the software VirtuoCity 2.4 , which was needed to run the virtual model. Each participant was randomly assigned to one of the 24 conditions. After navigating through the online simulation, the participant was asked to fill out a questionnaire.

\section{Measures.}

Pleasure, arousal, and dominance. Three emotional dimensions were measured on the basis of the Pleasure Arousal Dominance (PAD) scale (Mehrabian \& Russell, 1974). Pleasure was measured with 6 items. Participants could indicate on a 7-point scale to what extent they felt unhappyhappy, annoyed-pleased, unsatisfied-satisfied, melancholic- 

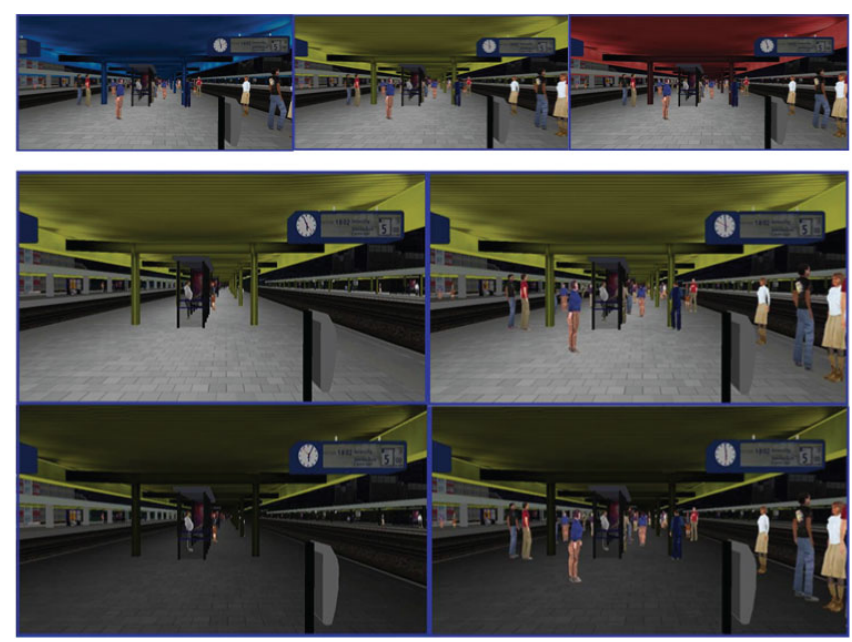

Figure 2. Blue, yellow and red canopies on the platform (above). The yellow platform is depicted with high intensity of light (above) and low intensity of light (below), and low density (left side) and high density (right side).

contended, despairing-hopeful, and unpleasant-pleasant; $\alpha=.92$ ). Arousal was measured with 7 items (stimulatedrelaxed, excited-calm, frenzied-sluggish, jittery-dull, wide awake-sleepy, aroused-unaroused; fit-tired; $\alpha=.72$ ). Dominance was measured with 6 items (controlled-controlling, influenced-influential, cared for-in control, awed-important, submissive-dominant, autonomous-guided; $\alpha=.76$ ).

Platform score. Station evaluation was assessed by asking participants to evaluate the platform by awarding a score on a 10 -point scale $(1=$ poor, $10=$ excellent $)$.

Cognitive appraisal of the wait. How the time on the platform was perceived was measured with the question "How did you experience the time spent at the station?" ( 1 = very short, 7 = very long) (cf., Pruyn \& Smidts, 1998).

Acceptable wait. Acceptable wait was measured with one item: "The time I spent on the platform was: $1=$ unacceptable, 7 = acceptable."

Utilitarian and hedonic waiting experience. Waiting time experience was measured on the basis of the hedonic and utilitarian attitude dimensions as suggested by Batra and Ahtola (1990). Hedonic waiting experience was measured with three items (7-point Likert scale, $\alpha=.92$ ) and utilitarian waiting experience was measured with three items ( $\alpha=.87)$. Examples of utilitarian waiting time items are "Was the time you spent waiting on the platform: $1=$ useful, 7 = useless; 1 = valuable, $7=$ worthless" Examples of the hedonic waiting experience: "Was the time you spent waiting on the platform: $1=$ pleasing, $7=$ annoying; $1=$ happy, 7 = sad"

\section{Results}

Manipulation check. Perceived density was measured with the aid of the perceived crowding scale (Harrell, Hutt \& Anderson, 1980), which consists of seven items. Examples are: "There are many passengers on the platform" and "On the platform I am limited in my freedom of movement" ( $1=$ totally disagree, $7=$ totally agree $\alpha=.79)$. The manipulation check confirmed that in the high density conditions, the station was rated as more crowded $(M=3.8, S D=.92)$ compared to the low density conditions $(M=3.01, S D=$ $.93 ; F(1,1314)=235.4, p<.001)$.

Station experience. A three color (blue vs. yellow vs. red) $\mathrm{x}$ two light intensity (low vs. high) $\mathrm{x}$ two motivational orientation ("must" vs. "lust") x two density (low vs. high) multivariate analysis of variance (MANOVA) was conducted with four dependent variables related to station experience (pleasure, arousal, dominance, platform score). The MANOVA revealed significant main effects for light intensity $(F(4,1277)=2.78, p=.03)$ and motivational orientation $(F(4,1277)=2.99, p=.02)$. A two-way interaction was found between color and motivational orientation $(F(8,2554)=2.05, p=.03)$, and a three-way interaction was found between color, motivational orientation and density $(F(8,2254)=2.25, p=.02)$. Remaining main and interaction effects were non significant. Follow up analyses were conducted using univariate analyses of variance (ANOVA).

Pleasure, arousal and dominance. An ANOVA showed that "lust" passengers experienced more dominance $(M=$ $4.33, S D=.73)$ than "must" passengers $(M=4.23, S D=$ $.75 ; F(1,1313)=5.58, p=.02)$. More importantly, another ANOVA revealed that passengers experienced more pleasure with a low light intensity $(M=4.58, S D=1.05)$ than with a high light intensity $(M=4.40, S D=1.04 ; F(1,1321)=$ $9.63, p=.002)$. The same applied to dominance: passengers experienced more dominance with a low light intensity $(M=$ $4.34, S D=.73)$ than with a high light intensity $(M=4.22$, $S D=.74 ; F(1,1313)=7.99, p=.005)$.

A significant two-way interaction between color and motivational orientation was found for arousal $(F(2,1309)=5.79$,
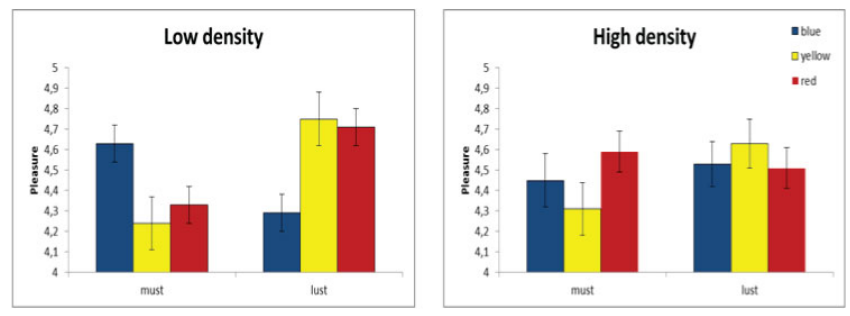

Figure 3. Pleasure as a function of color (blue, yellow, or red), motivational orientation ("must" vs. "lust") and density (low density vs. high density). Standard errors are presented in the figure by the error bars attached to each column. 
$p=.003)$. "Must" passengers were less stimulated by yellow $(M=4.23, S D=.95)$ than by red $(M=4.51, S D=$ $.84)$ or blue $(M=4.59, S D=.89 ; F(2,1309)=7.55, p=$ $.001)$. No significant arousal effect was found for "lust" passengers. For pleasure a significant two-way interaction $(F(2$, $1317)=7.02, p=.005$ ) was qualified by a three-way interaction between color, motivational orientation and density $(F(2,1311)=6.51, p=.002)$. Figure 3 shows that under a low density condition, "lust" passengers experienced greater pleasure with the colors yellow and red than with the color blue $(\mathrm{F}(2,1311)=7.29, p=.001)$, whereas "must" passengers experienced greater pleasure on a blue than on a yellow platform $(F(2,1311)=1.88, p=.02)$. Under high density conditions no differences were observed.

Platform score. A similar but only marginally significant three-way interaction was also found for platform score $(F(2,1303)=2.83, p=.06)$. Lust passengers appreciated yellow on the platform more than blue at quiet low-density moments $(F(2,1303)=3.68, p=.03)$. Although the results point in the right direction, we did not find any significant differences between the colors yellow and blue for "must" passengers $(F(2,1303)=1.80, p=.17)$. These findings are in accordance with reversal theory, which proposes that "lust" passengers are more receptive to environmental stimuli than "must" passengers.

Waiting experience. A three color (blue vs. yellow vs. red) $\mathrm{x}$ two light intensity (low vs. high) $\mathrm{x}$ two motivational orientation ("must" vs. "lust") x two density (low vs. high) MANOVA was also conducted with the dependent variables related to waiting experience (cognitive appraisal of the wait, acceptable wait, utilitarian and hedonic waiting time). The MANOVA revealed significant interactions between light intensity and motivational orientation $(F(10,2512)=2.51, p=.03)$, and light intensity and density $(F(5,1256)=2.76, p=.03)$. Marginally significant interaction effects were found between color and motivational orientation $(F(5,1256)=1.66, p=.08)$, and density and motivational orientation $(F(5,1256)=2.25, p=.06)$. Remaining main and interaction effects were non significant.

Cognitive appraisal of the wait and acceptable wait. ANOVAs showed that the combination of light intensity and density influenced acceptance of the wait $(F(1,1320)=$ $8.90, p<.01)$ and time perception $(F(1,1315)=5.58, p<$ .02 ). Figure 4 shows that on a busy (high density) platform the light intensity has hardly any influence on the acceptance of the waiting time or how the duration thereof is experienced. However, on the low density platform, the waiting time is experienced as more acceptable with a low rather than a high light intensity $(F(1,1320)=16.1, p=.000)$. Also the time on a low density platform seems to take less long with a low versus a high light intensity $(F(1,1315)=11.83, p=$ $.001)$. In quiet periods, a low light intensity would thus seem to result in positive effects for the waiting experience.
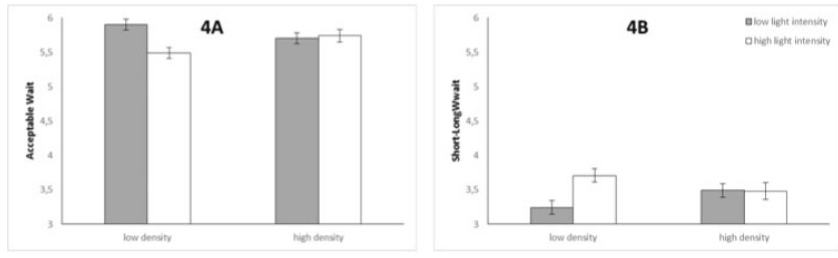

Figure 4. Acceptable waiting time $(1=$ unacceptable, $7=$ acceptable $)$ and cognitive appraisal of the wait $(1=$ short, 7 $=$ long) as a function of light intensity (low vs. high intensity of light) and density (low density vs. high density). Standard errors are presented in the figure by the error bars attached to each column.

Hedonic and utilitarian wait. ANOVAs revealed that the combination of color and motivational orientation does indeed influence both the hedonic $(F(2,1310)=6.77, p=$ $.001)$ and the utilitarian appraisal of waiting time $(F(2,1311)$ $=3.28, p=.04)$. Figure 5 shows that "lust" passengers experienced the waiting time on the yellow platform as more pleasant $(F(2,1310)=4.26, p=.01)$ and more useful $(F(2$, $1311)=3.43, p=.03$ ) than on the blue platform. In contrast, "must" passengers experienced a more pleasant waiting time $(F(2,1310)=3.06, p=.05)$ on the blue platform than on the yellow one.

\section{Discussion Study 1}

The effects of environmental stimuli depend on whether one is a "must" or "lust" passenger (and thus in a hurry or not). This study showed that regardless of light intensity, warm colors (both red and yellow) resulted in higher levels of pleasure and a more positive appraisal of the wait for "lust" passengers, which confirmed Hypothesis 1. Must passengers, on the other hand, experienced more pleasure with the color blue, as well as finding the wait more pleasant which confirmed Hypothesis 2.

The results particularly showed positive effects under dimmed lighting conditions. Regardless of color, a low density platform with a low light intensity affords a more positive

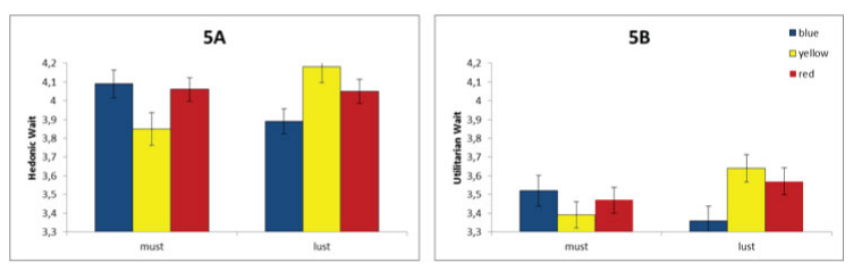

Figure 5. Hedonic wait and utitilarian wait as a function of color (blue, yellow or red) and motivational orientation ("must" vs. "lust"). Standard errors are presented in the figure by the error bars attached to each column. 
waiting experience than a low density platform with a high light intensity. Waiting on a quiet platform with a low light intensity is not only considered as being more acceptable but also the wait seems to be shorter. With a high light intensity, no differences were found for the waiting experience regardless of color or density. Light intensity and colors have thus no effect on the waiting experience when combined with density.

Overall, the findings from this research support reversal theory (Apter, 2007; Walters, Apter \& Svebak, 1982), which hypothesizes that people under pressure prefer cool colors and in a relaxed situation incline towards warm ones. The impact of colors thus appear to be dependent on the demand for stimuli, whereby "lust" passengers respond more positively to warm stimulating colors and "must" passengers to cool relaxing ones.

Also, dimly lit surroundings appear to evoke more positive affective reactions to the waiting time and the acceptance of the waiting time than when the lights are brighter. Moreover, time seems to pass more quickly in dimly lit situations than when the lights are brighter.

The results show that manipulations in a virtual environment successfully allow effects with color, light, density and time pressure to be demonstrated and that the findings are comparable with those from the field study (see Van Hagen, 2011).

\section{Study 2: Musical genre}

Besides atmospheric influences such as color and lighting, music has been acknowledged as one of the most important and effective elements in the servicescape. Music has been shown to be an effective means of influencing mood, behavior, and perception (Bruner, 1990). It is not only relatively easy to deploy and easy to control, but music has also been shown to positively impact a wide range of consumer responses in service settings (e.g., Garlin \& Owen, 2006), and more specifically in restaurants (Caldwell \& Hibbert, 2002; Milliman, 1986; North, Shilcock \& Hargreaves, 2003), banks (Dubé, Chebat \& Morin, 1995; North, Hargreaves \& McKendrick, 2000), wine stores (Areni \& Kim, 1993) and travel agencies (Bitner, 1990). However, in a simulated laboratory experiment, Cameron et al. (2013) showed that background music (in high and low volume levels) elicited a negative impact on service evaluation and had no impact on perceived wait duration. In the study by Cameron et al., classical music was used which calls into question whether classical music should be used in waiting environments. The authors suggest that perhaps other types of music that generate stronger affective responses would have elicited other responses in a service environment. This study investigates whether musical genre can influence the station and waiting experience by comparing two different genres, i.e., calming and stimulating music.

\section{Method}

Participants. Participants were panel members of the NS panel. The online assignment and questionnaire was fully completed by 517 members of the panel (58.9\% male, $41.4 \%$ female). The mean age of the panel members was 43 years $(S D=15.73)$

Design and stimulus materials. In a three musical genre (stimulating vs. calming vs. no music) x two motivational orientation ("must" vs. "lust") x two density (low vs. high) between-subjects design we studied what influence the differences in musical genre have on the passenger's waiting and station experience. As in study 1, the participants were asked to navigate through a virtual simulation of Leiden Central station. In study 2, the virtual station had a 10minute cycle (running from 17:52-18:02 hrs), after which the train departed. Test subjects entered this cycle at an arbitrary moment (depending on their self-chosen login moment) and thus had a different objective waiting time. Whilst the test subjects navigated through the station, their objective waiting time at both the station (from the entrance to clicking on the train) and on the platform (from their first step on it to the time they clicked on the train) was recorded to within a second.

The same procedures and manipulations were used to induce motivational orientation and density. In this study, participants were explicitly requested to adjust the sound on their computer (to a comfortable volume) before entering the virtual world. Half of the subjects listened to calming tracks, whereas the other half were allocated stimulating pieces of music. How music is experienced does not solely depend on music tempo (as indicated by beat per minute, BPM), but also on the subjective impression thereof. The subjective interpretation of BPM is evident with dance, for example: with certain songs, people dance twice as slow as the beat (BPM), and the music is perceived as 'half tempo' (or half time). This interpretation occurs simultaneously among large groups of people and is not restricted to culture or place. In musical terms, the subjective tempo is indicated by a type of meter and tempo that alters the rhythmic feel by essentially doubling the tempo resolution. Thus $4 / 4$ approximates $8 / 8$. The subjective BPM determines whether music is found to be relaxing or stimulating. Six tracks per genre were played at random. The tracks were easy listening music tracks and selected by a music expert. The selection criteria for the track concerned the emotional tone (melodical complexity, rhythmic complexity, vocal meaningfulness, and consonant harmony), whereas other criteria such as volume, tempo and pitch (Bruner, 1990) were kept as similar as possible in order to prevent confounding effects.

Measures. In this study the same measures were used as in study 1. Table 2 shows the Coefficient alpha's, the minimum and maximum values, the mean and standard deviations of each of the constructs. In study 2 we were able to record 
Table 2

Cronbach's Alpha, Min., Max., M and SD of the dependent variables

\begin{tabular}{lccccc}
\hline Station experience & $\alpha$ & Min. & Max. & $M$ & $S D$ \\
\hline Pleasure & .89 & 1 & 7 & 4.4 & .90 \\
Arousal & .81 & 1 & 6 & 3.5 & .88 \\
Dominance & .8 & 1 & 7 & 3.9 & .77 \\
Platform score & - & 1 & 10 & 7.2 & 1.23 \\
\hline Waiting experience & & & & & \\
Time perception (in minutes) & - & 0 & 20 & 3.8 & 3.00 \\
Cognitive appraisal of the wait & - & 1 & 7 & 3.5 & 1.69 \\
Acceptable wait & - & 1 & 7 & 4.9 & 1.36 \\
Utilitarian waiting experience & .93 & 1 & 7 & 3.1 & 1.41 \\
Hedonic waiting experience & .93 & 1 & 7 & 3.9 & 1.23 \\
\hline
\end{tabular}

the objective time spent at the (virtual) station and platform. Therefore we included an extra item to measure subjective time experience with an open question: "If you had to guess, how long do you think you were at the platform (in minutes)?"

\section{Results}

Manipulation checks. Of the 517 experimental subjects, $426(82.4 \%)$ were in a condition with music. The other 91 subjects $(17.6 \%)$ were in a condition without music. Of the 426 subjects in a condition with music, 298 of them (57.6\%) reported they had heard music.

To determine whether the quiet versus busy platform was indeed experienced as such, a manipulation check was conducted. Three items of the perceived crowding scale (Harrell, Hutt \& Anderson, 1980) were incorporated in the questionnaire in order to ascertain the perceived crowding $(\alpha=.79)$. For example: "There are many passengers on the platform." An ANOVA showed that experimental subjects in the high density condition rated the platform as more crowded $(M=$ $3.02, S D=1.38)$ than subjects in the low density condition $(M=2.22, S D=1.18), F(1,499)=48.25, p=.000)$,

Also a manipulation check was carried out to ascertain whether stimulating music was indeed assessed as being more stimulating than calming music. An analysis of variance showed that stimulating music was indeed experienced as being more stimulating $(M=4.54, S D=1.19)$ than calming music $(M=3.93, S D=1.49), F(1,208)=11.02, p=$ $.001)$.

Station experience. A two motivational orientation ("must" vs. "lust") x two density (low vs. high) x three musical genre (stimulating vs. calming vs. no music) MANOVA with the dependent variables relating to station experience (pleasure, arousal, dominance and station score) revealed only a significant interaction effect between musical genre and density $(F(8,670)=3.72, p=.001)$. Any other main and interaction effects on station experience were non significant.

Pleasure and arousal. As the degree of stimulation influences the hedonic tone, we will first look at the results of arousal. An interaction effect was found between music and density on arousal $(F(2,338)=6.43, p=.002)$. As can be seen in Figure 6, on busy platforms passengers experienced more arousal with stimulating music than with calming music and no music $(F(2,344)=8.41, p=.000)$. This difference is non-significant on a quiet platform. The interaction plot clearly shows how density and stimulating music incite extra stimuli.

Musical genre in combination with density influenced pleasure $(F(2,338)=9.56, p=.000)$. Passengers on low density platforms experienced greater pleasure when stimulating or no music was played in comparison with calming music $(F(2,343)=4.42, p=.01)$. At high density platforms passengers experienced more pleasure when calming or no music was played in comparison with stimulating mu$\operatorname{sic}(F(2,343)=7.71, p=.001)$. There were no significant findings for dominance.

Station score. Musical genre in combination with density influenced the hedonic tone, not only for pleasure but also for the station score $(F(2,338)=6.51, p=.001)$. An ANOVA revealed that at low density platforms passengers rated the station with a higher score when stimulating music was played as compared with calming music $(F(2,345)=$ $3.47, p=.03)$. No significant differences were found with the condition without music. At high density platforms passengers awarded the station a higher score when no music was played as opposed to stimulating music $(F(2,345)=$ $3.97, p=.02)$. There were no significant differences with the calming music condition.

Waiting experience. A two motivational orientation ("must" vs. "lust") x two density (low vs. high) x three musi-

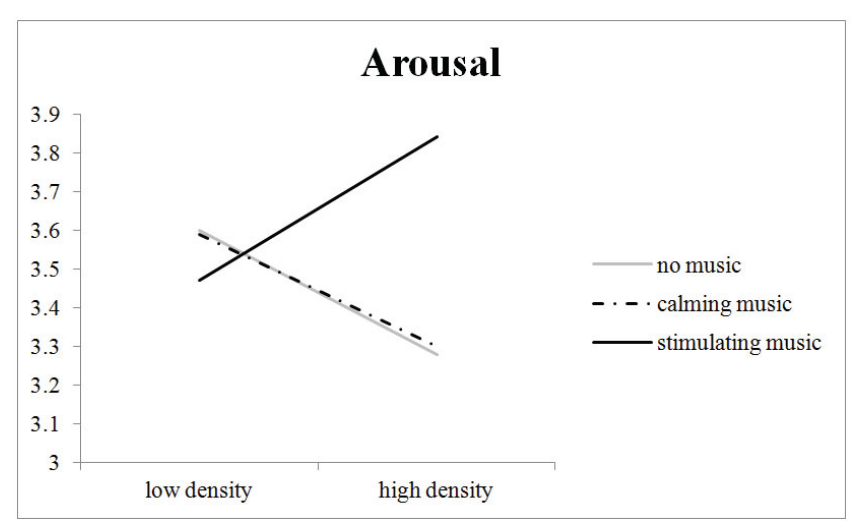

Figure 6. Arousal as a factor of musical genre (no music, calming or stimulating music) and density (low density vs. high density). 
cal genre (stimulating vs. calming vs. no music) MANOVA on waiting experience (utilitarian and hedonic wait, acceptable wait, cognitive appraisal of the wait, subjective time experience) revealed a marginally significant interaction effect between music and motivational orientation $(F(12,638)=$ $2.51, p=.06)$, and a three-way interaction between density, music, and motivational orientation $(F(12,638)=1.79, p=$ $.05)$. The other main and interaction effects were non significant.

Objective and subjective time. This study also recorded the objective time. On average respondents spent $7.05 \mathrm{~min}-$ utes $(S D=4.18)$ at the station, of which an average 4.05 minutes $(S D=3.30)$ were on the platform. A t-test revealed a significant difference between the objective and subjective time on the platform $(t(516)=28.30, p=.000)$. The time on the platform appeared to be significantly longer than the actual or objective time. On average, passengers overestimated their waiting time, which is in keeping with the literature (Hornik, 1984, 1992).

Acceptable and subjective time experience. An interaction was found between music and motivational orientation on the subjective time experience on the platform $(F(2,319)$ $=4.79, p=.01)$. An ANOVA revealed that with stimulating music "lust" passengers estimated their waiting time as shorter than with calming music $(F(2,344)=3.45, p=.03)$. There was no significant difference with the condition without music nor were significant differences found for "must" passengers. Another ANOVA also revealed a significant interaction effect for acceptable wait $(F(2,319)=3.31, p=.03)$ which shows that "lust" passengers found the waiting time on the platform more acceptable when there was stimulating music or no music as compared with calming music $(F(2$, $338)=3.59, p=.03$ ). This difference was non-significant for "must" passengers.

Hedonic wait. A marginally significant three-way interaction effect was found between music, density and motivational orientation on hedonic appraisal of the wait $(F(2,319)$ $=2.91, p=.06$ ). Figure 7 shows that "lust" passengers spent their waiting time more pleasantly when stimulating music was played as compared with calming or no music $(F(2,333)$ $=7.10, p=.001)$. When it was busy, "lust" passengers indicated they spent their waiting time more pleasantly when no music was played than with stimulating or calming music $(F(2,333)=3.25, p=.04)$. These differences were nonsignificant for "must" passengers.

Discussion study 2. The assumption of this study was that by playing the right music on a platform, waiting passengers would be offered an optimal level of stimuli which would result in a more positive station and waiting experience. With an optimal level of stimuli the hedonic tone (much pleasure, high score) is raised. In order to achieve the optimal level of stimuli the context is of importance: reversal theory predicts that stimulating music at quiet moments and calming music at busy moments has a positive

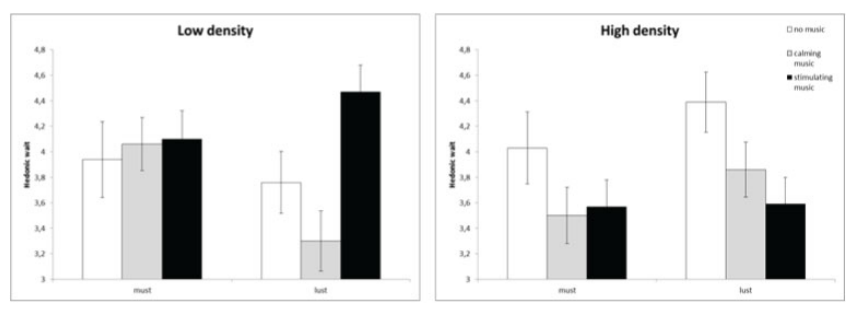

Figure 7. Hedonic wait as a function of musical genre (no music, calming music or stimulating music), motivational orientation ("must" vs. "lust") and density (low density vs. high density). Standard errors are presented in the figure by the error bars attached to each column.

effect. This also applies to the type of passenger: "lust" passengers are more receptive to environmental stimuli and it is to be expected that they prefer stimulating music during the wait, whereas "must" passengers are less receptive to extra environmental stimuli and will have a greater preference for calming music. A more positive hedonic tone has an effect on the waiting experience; if the passengers experience pleasure, then they will experience the wait more positively (the waiting time is more pleasant and more acceptable), and the wait will seem to be shorter (Baker \& Cameron, 1996; Hornik, 1992).

Our findings concur with reversal theory. It is indeed at low-density moments that stimulating music results in a higher hedonic tone(greater pleasure and a higher station score) than calming music, just as it is at busy high-density moments that passengers experience greater pleasure when calming music is played, as opposed to stimulating music (Van Hagen, 2011). Figure 8 shows how the musical genres and the degree of density are related to the degree of stimulation (arousal) and hedonic tone.

In accordance with reversal theory, calming music appears to result in a more positive waiting experience for "must"

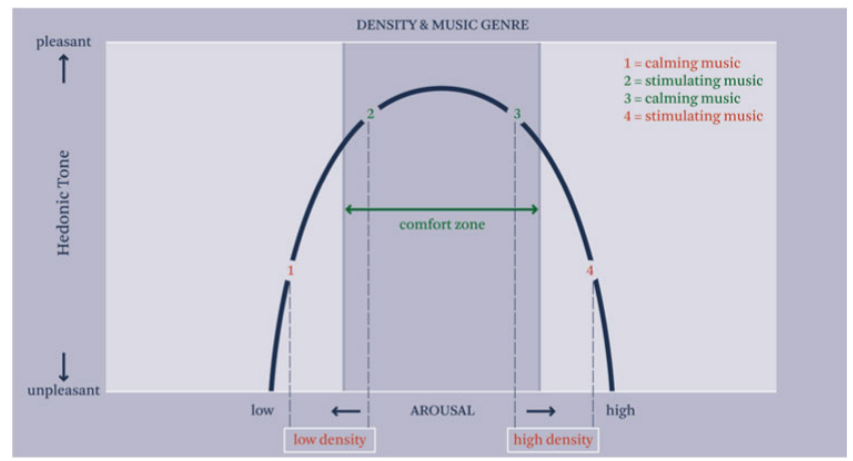

Figure 8. Density and music genre related to arousal and hedonic tone. 
passengers, just as stimulating music does for "lust" passengers. This applies to the acceptance of the waiting time and to a pleasant wait. "Lust" passengers find the waiting time more acceptable and pleasant with stimulating music than with calming music. This result supports the premise of reversal theory when applied to the type of passenger: "lust" passengers are receptive to environmental stimuli. If this need of stimuli is met, then the pleasure increases and the waiting experience is improved. Also apparent is that "lust" passengers estimate the time as being shorter with stimulating as opposed to calming music, which supports Hypothesis 3. This not only concurs with the attentional model (Zakay \& Block, 1997) but also with reversal theory(Apter, 2007). For "lust" passengers stimulating music affords sufficient distraction, causing them to pay less attention to the time and hence underestimate its duration (attentional model). Lust passengers apparently have a greater need of environmental stimuli and/or allow themselves to be distracted, and this concurs with reversal theory. A more pleasant wait and greater acceptance of the waiting time result in a more positive hedonic tone whereby "lust" passengers underestimate the time (Baker \& Cameron, 1996; Hornik, 1984; 1992; 1993).

\section{General discussion}

Overall, the studies revealed that when platforms are busy, the number of stimuli should be minimized, but when it is quiet, stimuli should be added. For instance, at quiet moments passengers experienced greater pleasure when stimulating music was played, whereas at busy moments it was the other way round (i.e., greater pleasure when calming music was played). Warm stimulating colors (i.e., red and yellow) were associated with pleasure, but only for "lust" (non hasty) passengers. In contrast, "must" (hasty) passengers leant more towards the calming color blue. These findings lent support for Hypotheses 1 and 2, and concur with those of Massara, Liu and Melara (2010). They can be successfully explained with reversal theory whereby mildly incongruent stimuli afford the most positive station evaluation and waiting experience. It became evident that stimulating music and warm colors at quiet moments result in greater pleasure than calming music and cool colors.

\section{Environmental stimuli and time perception}

Lust passengers seemed more receptive to stimulating environments. Under these circumstances pleasure increased, and the waiting experience improved. Findings from study 2 showed that "lust" passengers estimated the time as being shorter with stimulating as opposed to calming music, which confirmed Hypothesis 3.

However, the studies also demonstrated that waiting time sometimes seems to pass more quickly in an environment with calming stimuli as well as in an environment with stimulating stimuli. Time seemed to pass more quickly with the barely stimulating color blue and dimmed lighting, whereas in the music study time appeared to pass more quickly with stimulating music on a busy platform. Several explanations may be given for these (apparently) opposite results and the way stimuli are processed might be responsible for these effects, in which conscious or unconscious processing of environmental stimuli plays a role. For example, we know that conscious attention plays a role when estimating time. Conscious attention to time probably played a role in our studies, albeit that any contrast was determined by the kind of environmental stimuli. Although every stimulus in the environment is perceived and influences behavior, selective attention allows only a few to reach our consciousness. When environmental stimuli are barely consciously perceived (such as cool colors and a low level of lighting) one's attention is not consciously distracted from the time. However, a more stimulating environment (with warm colors and a high level of lighting) does afford more information processing. Ornstein's storage size model (1969) might offer an explanation here in which more information processing results in a longer estimation of the duration. When attention is consciously distracted from the time, such as with music, passengers notice their environment more and can even experience a moment of 'flow'. As less processing capacity remains to follow the time, it seems to pass more quickly. Here, in accordance with the attentional model, and as with the prospective approach, distraction from the time affords a shorter estimation of the duration.

Although reversal theory (Apter, 2007) paid no attention to the experience of time, it might still explain our findings. Both few and many stimuli can afford a higher hedonic tone in the shape of relaxation (few stimuli) or excitement (many stimuli) and make time seemingly pass more quickly. Our studies have shown that the test subjects indeed experienced greater pleasure not only with dimmed lighting but also with stimulating music.

Combining aforementioned explanations implies that as satisfied passengers do not pay attention to the time, it seems to pass more quickly (attentional model). Relaxed passengers neither (consciously) heed the time nor their surroundings and are probably so deep in thought that they also estimate the time as shorter (storage size model). Passengers with a low hedonic tone overestimate the time because they are bored due to a long wait or because the wait itself induces stress. Figure 9 shows the relations with the research findings and theories on waiting time.

The studies we presented here were conducted in a virtual environment. Besides the advantage of conditioned surroundings, a virtual station had the benefit that various environmental elements could be manipulated relatively cheap (as opposed to a real life field study). With its visual images, ambient sounds and freedom of movement, the virtual environment offered a comparable to life representation of reality 


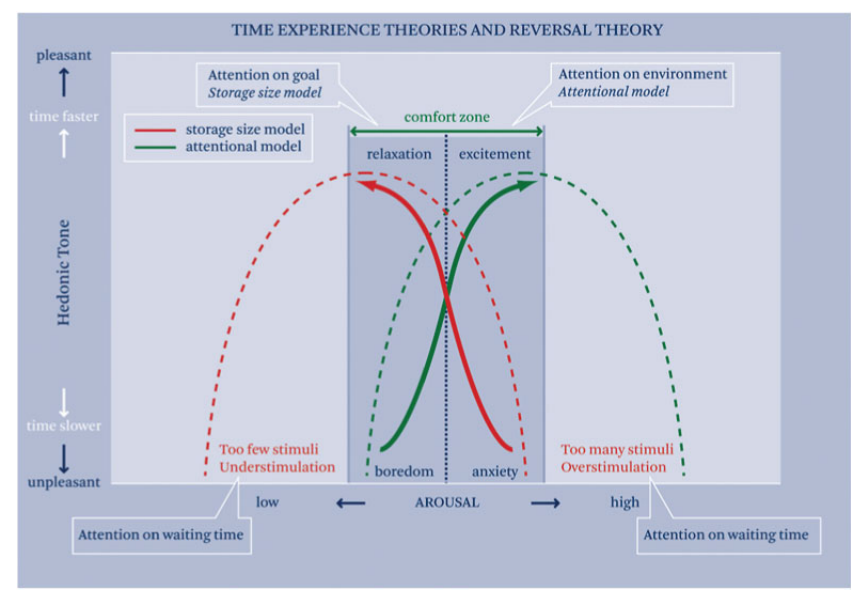

Figure 9. Relationship research findings and theories on waiting time.

(Blascovich, et al., 2002; Massara et al., 2010; Rivaet al., 2006). Another benefit of the virtual environment was that it was possible to record the objective duration of stay at the station and on the platform. Moreover a practical advantage of an online enquiry was its extensive reach - a large and widespread group of test subjects in a short period of time (Gosling, Vazire, Srivastava \& John, 2004; Kraut, Olson, Banaji, Bruckman, Cohen \& Couper, 2003). Last but not least, many different simulations could be implemented (i.e., the test subjects were asked to take a certain train and to imagine themselves in goal-directed "must" or a non goal-directed "lust" scenario). Also the degree of density (busy/quiet) was varied in the studies.

However, a virtual environment also has its disadvantages. Respondents need certain skills to manoeuvre through the station with the aid of mouse or arrow keys (Huang \& Claramunt, 2005; Loomis, Blascovich \& Beall, 1999). Moreover, all test subjects performed their tasks from behind their own computer, which means the screen and volume settings cannot be influenced, nor other possibly distracting environmental variables. A last disadvantage might be that subjects like walking around in the virtual environment which influences their mental state.. "Must" passengers might be in the paratelic state instead of the telic state. The results presented are significant and in the predicted direction, however the effect sizes were rather small. The virtual environment allowed us to demonstrate that subtle changes in the environment (color, light intensity or music genre) had an impact -albeit small- on the waiting experience of the subjects, even when they were not consciously aware of the manipulation. We expect that the impact will be larger when various stimuli are changed at the same time.

Overall, the results of the studies shed light on the relationship between environmental stimuli and waiting experi- ence, including the differentiation between busy and quiet surroundings and motivational states of passengers. Adding the correct environmental stimuli to the platform at the right time increases a pleasant waiting experience. In line with reversal theory, it can be concluded that the effects of environmental stimuli in waiting surroundings depend on the motivational state a person is in (Apter, 2007; Kerr \& Tacon, 1999; Kerr, Hayashi, Matusmoto, \& Miyamoto, 2002). Designers of waiting environments might choose to design an environment that reverses the negative emotions of boredom or stress to positive emotions of excitement and relaxation, and thus distract consumers from time (e.g., Fokkingka \& Desmet, 2013). In the design of waiting environments, it is our challenge to re-direct the goal oriented focus on time, and make people enjoy their stay. For this reversal from one state of mind to another, people first need to be in a 'protective frame', that is a frame that prevents waiting customers from being too late. They need to be in a 'safe zone' in which they can forget about time, and do not need to worry about being too late, or missing their train. On a platform different zones can be appointed in which different intensities of stimulation are presented, so passengers can choose the environment which suits their mental state best. On platforms, "must" passengers look for cues to determine where and when their train will leave. A good station layout and efficient information services allow these passengers to orientate themselves quickly and prevents unnecessary confusion (Nie, 2000). For "lust" passengers who might get bored when they experience too little stimulation, more stimuli can be added, which allows a reversal from boredom to excitement. The moment "must" and "lust" passengers feel reassured, reversal to a more playful or relaxing state of mind is possible in which consumers enjoy or appreciate an entertaining or relaxing waiting environment.

\section{References}

Adams, F. M., \& Osgood, C. E. (1973). A crosscultural study of the affective meanings of color. Journal of Cross-Cultural Psychology, 4(2), 135-156. doi: 10.1177/002202217300400201

Ang, S. H., Leong, S. M., \& Lim, J. (1997). The mediating influence of pleasure and arousal on layout and signage effects: Comparing more and less customized retail services. Journal of Retailing and Consumer Services, 4(1), 13-24. doi: http://dx.doi.org/10.1016/0969-6989(95)00091-7

Apter, M. J. (2007). Reversal Theory: The Dynamics of Motivation, Emotion and Personality, (2nd. Edition ed.). Oxford: Oneworld Publications.

Areni, C. S., \& Kim, D. (1993). The influence of background music on shopping behavior: Classical versus top-forty music in a wine store. Advances in Consumer Research, 20, 336-340. 
Bailey, N., \& Areni, C. S. (2006). When a few minutes sound like a lifetime: Does atmospheric music expand or contract perceived time? Journal of Retailing, 82(3), 189-202. doi: http://dx.doi.org/10.1016/j.jretai.2006.05.003

Baker, J., \& Cameron, M. (1996). The effects of the service environment on affect and consumer perception of waiting time: An integrative review and research propositions. Journal of the Academy of Marketing Science, 24(4), 338349. doi: $10.1177 / 0092070396244005$

Baker, J., \& Wakefield, K. (2012). How consumer shopping orientation influences perceived crowding, excitement, and stress at the mall. Journal of the Academy of Marketing Science, 40(6), 791-806. doi: 10.1007/s11747011-0284-z

Bateson, J. E. G., \& Hui, M. K. (1992). The ecological validity of photographic slides and videotapes in simulating the service setting. Journal of Consumer Research, 19(2), 271-281. doi: $10.2307 / 2489333$

Batra, R., \& Ahtola, O. T. (1990). Measuring the hedonic and utilitarian sources of consumer attitudes. Marketing Letters, 2(2), 159-170. doi: 10.1007/bf00436035

Biner, P. M., Butler, D. L., Fischer, A. R., \& Westergren, A. J. (1989). An arousal optimization model of lighting level preferences: An interaction of social situation and task demands. Environment and Behavior, 21(1), 3-16. doi: 10.1177/0013916589211001

Bitner, M. J. (1990). Evaluating service encounters: The effects of physical surroundings and employee responses. Journal of Marketing, 54, 69-82.

Blascovich, J., Loomis, J., Beall, A. C., Swinth, K. R., Hoyt, C. L., \& Bailenson, J. N. (2002). Immersive virtual environment technology as a methodological tool for social psychology. Psychological Inquiry, 13(2), 103-124. doi: 10.1207/S15327965PLI1302_01

Bruner II, G. C. (1990). Music, mood, and marketing. Journal of Marketing, 54(4), 94-105.

Butler, D. L., \& Biner, P. M. (1987). Preferred lighting levels: Variability among settings, behaviors, and individuals. Environment and Behavior, 19(6), 695-721. doi: 10.1177/0013916587196003

Caldwell, C., \& Hibbert, S. A. (2002). The influence of music tempo and musical preference on restaurant patrons' behavior. Psychology and Marketing, 19(11), 895-917. doi: 10.1002/mar.10043

Cameron, M., Baker, J., \& Peterson, M. (2013). Waiting for service: The effects of music volume and gender. Services Marketing Quarterly, 34(4), 257-273. doi: 10.1080/15332969.2013.827009

Chebat, J.-C., Filiatrault, P., Gélinas-Chebat, C., \& Vaninsky, A. (1995). Impact of waiting attribution and consumer's mood on perceived quality. Journal of Business Research, 34(3), 191-196. doi: http://dx.doi.org/10.1016/01482963(95)98346-4
Dion, D. (2004). Personal control and coping with retail crowding. International Journal of Service Industry Management, 15(3), 250-263. doi: 10.1108/09564230410540926

Dubé, L., Chebat, J.-C., \& Morin, S. (1995). The effects of background music on consumers' desire to affiliate in buyer-seller interactions. Psychology and Marketing, 12(4), 305-319. doi: 10.1002/mar.4220120407

Elliot, A. J., \& Maier, M. A. (2014). Color psychology: Effects of perceiving color on psychological functioning in humans. Annual Review of Psychology, 65(1), 95-120.

Fokkinga, S., \& Desmet, P. (2013). Ten ways ot design for disgust, sadness, and other enjoyments: A design approach to enrich product experiences with negative emotions. International Journal of Design, 7(1), 19-36.

Folkes, V. S. (1984). Consumer reactions to product failure: An attributional approach. Journal of Consumer Research, 10(4), 398-409. doi: 10.2307/2488909

Huang, B., \& Claramunt, C. (2005). Spatiotemporal data model and query language for tracking land use change. Transportation Research Record, 1902,107-113.

Gardner, M. P. (1985). Mood states and consumer behavior: A critical review. Journal of Consumer Research, 12(3), 281-300. doi: $10.2307 / 254374$

Garlin, F. V., \& Owen, K. (2006). Setting the tone with the tune: A meta-analytic review of the effects of background music in retail settings. Journal of Business Research, 59(6), 755-764. doi: http://dx.doi.org/10.1016/j.jbusres.2006.01.013

Gosling, S.D., Vazire, S., Srivastava, S., \& John, O.P. (2004). Should we trust web-based studies? A comparative analysis of six preconceptions about internet questionnaires. American Psychologist, 59(2), 93-104.

Grewal, D., Baker, J., Levy, M., \& Voss, G. B. (2003). The effects of wait expectations and store atmosphere evaluations on patronage intentions in service-intensive retail stores. Journal of Retailing, 79(4), 259-268. doi: http://dx.doi.org/10.1016/j.jretai.2003.09.006

Harrell, G. D., Hutt, M. D., \& Anderson, J. C. (1980). Path analysis of buyer behavior under conditions of crowding. Journal of Marketing Research, 17(1), 45-51. doi: $10.2307 / 3151115$

Hornik, J. (1984). Subjective vs. objective time measures: A note on the perception of time in consumer behavior. Journal of Consumer Research, 11(1), 615-618. doi: $10.2307 / 2489149$

Hornik, J. (1992). Time estimation and orientation mediated by transient mood. The Journal of Socio-Economics, 2l(3), 209-227. doi: http://dx.doi.org/10.1016/10535357(92)90010-5

Hui, M. K., \& Bateson, J. E. G. (1991). Perceived control and the effects of crowding and consumer choice on the 
service experience. Journal of Consumer Research, 18(2), 174-184. doi: 10.2307/2489553

Hui, M. K., Dube, L., \& Chebat, J.-C. (1997). The impact of music on consumers' reactions to waiting for services. Journal of Retailing, 73(1), 87-104. doi: 10.1016/S00224359(97)90016-6

Jacobs, K. W., \& Suess, J. F. (1975). Effects of four psychological primary colors on anxiety state. Perceptual and Motor Skills, 41(1), 207-210. doi: 10.2466/pms.1975.41.1.207

Katz, K. L., Larson, B. M., \& Larson, R. C. (1991). Prescription for the waiting-in-line blues: entertain, enlighten, and engage. Sloan Management Review, 32(2), 44-53.

Kerr, J. H., Hayashi, T., Matsumoto, M., \& Miyamoto, N. (2002). The influence of settings and environmental events on metamotivational state and arousal: Further tests of reversal theory on Asian samples. Journal of Environmental Psychology, 22(4), 361-367. doi: http://dx.doi.org/10.1006/jevp.2002.0275

Kerr, J. H., \& Tacon, P. (1999). Psychological responses to different types of locations and activities. Journal of Environmental Psychology, 19(3), 287-294. doi: 10.1006/jevp.1999.0132

Kraut, R.E., Olson, J., Banaji, M., Bruckman, A., Cohen, J., $\&$ Couper, M. (2003). Psychological research online: Opportunities and challenges. Report prepared for the American Psychological Association's Taskforce on the Internet and Psychological Research. Retrieved August 28, 2003, from http://www-2.cs.cmu.edu/afs/cs.cmu.edu/user/kraut/ www/ Krraut.site.files/articles/kraut03PsychologicalResearchOnline.pdf

Loomis, J., Blascovich, J., \& Beall, A. (1999). Immersive virtual environment technology as a basic research tool in psychology. Behavior Research Methods, Instruments, $\mathcal{E}$ Computers, 31, 557-564.

Massara, F., Liu, S. S., \& Melara, R. D. (2010). Adapting to a retail environment: Modeling consumer-environment interactions. Journal of Business Research, 63(7), 673681. doi: 10.1016/j.jbusres.2009.05.004

Loomis, J., Blascovich, J. \& Beall, A. (1999). Immersive virtual environment technology as a basic research tool in psychology. Behavior Research Methods, Instruments, $\mathcal{E}$ Computers, 31, 557-564.

Mackie, P.J., Fowkes, A.S., Wardman, M., Whelan, G., \& Bates J. (2001). Values of travel time savings in the UK. Leeds, UK: Institute for Transport Studies, University of Leeds.

Mayer, J. D., Gaschke, Y. N., Braverman, D. L., \& Evans, T. W. (1992). Mood-congruent judgment is a general effect. Journal of Personality and Social Psychology, 63(1), 119132. doi: $10.1037 / 0022-3514.63 .1 .119$

Mehrabian, A., \& Russell, J. (1974). An Approach to Environmental Psychology. Cambridge, Mass.: MIT Press.
Milliman, R. E. (1986). The influence of background music on the behavior of restaurant patrons. Journal of Consumer Research, 13(2), 286-289. doi: 10.2307/2489234

Nie, W. (2000). Waiting: Integrating social and psychological perspectives in operations management. Omega, 28(6), 611-629.

North, A. C., Hargreaves, D. J., \& McKendrick, J. (2000). The effects of music on atmosphere in a bank and a bar. Journal of Applied Social Psychology, 30(7), 1504-1522. doi: $10.1111 / \mathrm{j} .1559-1816.2000 . t b 02533 . x$

North, A. C., Shilcock, A., \& Hargreaves, D. J. (2003). The effect of musical style on restaurant customers' spending. Environment and Behavior, 35(5), 712-718. doi: 10.1177/0013916503254749

Ornstein, R. E. (1969). On the Experience of Time. New York: Penguin Books.

Peek, GJ \& Hagen, M van (2002). Creating synergy in and around stations. Three strategies for adding value. Transportation Research Record, 1-6.

Pons, F., Laroche, M., \& Mourali, M. (2006). Consumer reactions to crowded retail settings: Cross-cultural differences between North America and the Middle East. Psychology and Marketing, 23(7), 555-572. doi: 10.1002/mar.20146

Proshansky, H. M., Ittelson, W. H., \& Rivlin, L. G. (1976). Environmental Psychology: People and Their Physical Settings (2nd ed.). Oxford: Holt, Rinehart \& Winston.

Pruyn, A., \& Smidts, A. (1998). Effects of waiting on the satisfaction with the service: Beyond objective time measures. International Journal of Research in Marketing, 15(4), 321-334. doi: 10.1016/S0167-8116(98)00008-1

Riva, G., Mantovani, F., Capideville, C. S., Preziosa, A., Morganti, F., Villani, D., . . . Alcañiz, M. (2007). Affective interactions using virtual reality: the link between presence and emotions. CyberPsychology $\mathcal{E}$ Behavior, 10(1), 45-56. doi: 10.1089/cpb.2006.9993

Steg, L. (2005). Car use: lust and must. Instrumental, symbolic and affective motives for car use. Transportation Research Part A: Policy and Practice, 39(2-3), 147-162. doi: http://dx.doi.org/10.1016/j.tra.2004.07.001

Stokols, D. (1972). On the distinction between density and crowding: Some implications for future research. Psychological Review, 79(3), 275-277. doi: 10.1037/h0032706

Surprenant, C. F., \& Solomon, M. R. (1987). Predictability and personalization in the service encounter. Journal of Marketing, 51(2), 86-96.

Taylor, S. (1994). Waiting for service: The relationship between delays and evaluations of service. Journal of Marketing, 58(2), 56.

Taylor, S. (1995). The effects of filled waiting time and service provider control over the delay on evaluations of service. Journal of the Academy of Marketing Science, 23(1), 38-48. doi: 10.1007/bf02894610 
Turley, L. W., \& Milliman, R. E. (2000). Atmospheric effects on shopping behavior: A review of the experimental evidence. Journal of Business Research, 49(2), 193-211. doi: 10.1016/S0148-2963(99)00010-7

Valdez, P., \& Mehrabian, A. (1994). Effects of color on emotions. Journal of Experimental Psychology: General, 123(4), 394-409. doi: 10.1037/0096-3445.123.4.394

Van Bommel, W., \& Van den Beld, G. (2004). Lighting for work: A review of visual and biological effects. Lighting Research and Technology, 36(4), 255-266. doi: 10.1191/1365782804li122oa

Van Hagen, M. (2011). Waiting experience at train stations. Dissertation, University of Twente, Enschede.

Van Rompay, T. J. L., Galetzka, M., Pruyn, A. T. H., \& Garcia, J. M. (2008). Human and spatial dimensions of retail density: Revisiting the role of perceived control. Psychology and Marketing, 25(4), 319-335. doi: 10.1002/mar.20211

Walters, J., Apter, M., \& Svebak, S. (1982). Color preference, arousal, and the theory of psychological reversals. Motivation and Emotion, 6(3), 193-215. doi: 10.1007/bf00992245

Ward, J. C., \& Barnes, J. W. (2001). Control and affect: the influence of feeling in control of the retail environment on affect, involvement, attitude, and behavior. Journal of
Business Research, 54(2), 139-144. doi: 10.1016/S01482963(99)00083-1

Wardman, M. (2004). Public transport values of time. Transport Policy, 11(4), 363-377. doi: http://dx.doi.org/10.1016/j.tranpol.2004.05.001

Worchel, S., \& Yohai, S. M. L. (1979). The role of attribution in the experience of crowding. Journal of Experimental Social Psychology, 15(1), 91-104. doi: 10.1016/00221031(79)90021-0

Yildirim, K., Hidayetoglu, M. L., \& Capanoglu, A. (2011). Effects of interior colors on mood and preference: Comparisons of two living rooms. Perceptual and Motor Skills, 112(2), 509-524. doi: 10.2466/24.27.pms.112.2.509-524

Zakay, D. (1989). Subjective time and attentional resource allocation: An integrated model of time estimation. In I. P. Levin \& D. Zakay (Eds.), Time and Human Cognition: A Life Span Perspective (pp. 365-395). Amsterdam, NL: Elsevier.

Zakay, D., \& Block, R. A. (1997). Temporal Cognition. Current Directions in Psychological Science, 6(1), 12-16. doi: 10.1111/1467-8721.ep11512604

Zakay, D., \& Block, R. A. (2004). Prospective and retrospective duration judgments: An executive-control process. Acta Neurobiologiae Experimentalis, 64, 319-328. 